\section{RMD Open}

Rheumatic \&

Musculoskeletal Diseases

\title{
Call for action: incorporating wellness practices into a holistic management plan for rheumatoid arthritis-going beyond treat to target
}

\author{
Peter C. Taylor (1D , ${ }^{1}$ Mart Van de Laar, ${ }^{2}$ Andrew Laster, ${ }^{3}$ Walid Fakhouri, ${ }^{4}$ \\ Amanda Quebe (D) , Inmaculada de la Torre, ${ }^{4}$ Saundra Jain ${ }^{5}$
}

To cite: Taylor PC, Van de Laar M, Laster A, et al. Call for action: incorporating wellness practices into a holistic management plan for rheumatoid arthritis—going beyond treat to target. RMD Open 2021;7:e001959. doi:10.1136/ rmdopen-2021-001959

Received 22 September 2021 Accepted 23 November 2021

Check for updates

(c) Author(s) (or their employer(s)) 2021. Re-use permitted under CC BY-NC. No commercial re-use. See rights and permissions. Published by BMJ.

${ }^{1}$ Botnar Research Centre, NDORMS, University of Oxford, Oxford, UK

${ }^{2}$ Transparency in Healthcare B.V University of Twente, Hengelo, The Netherlands

${ }^{3}$ Arthritis \& Osteoporosis Consultants of the Carolinas, Charlotte, North Carolina, USA ${ }^{4}$ Eli Lilly and Company, Indianapolis, Indiana, USA ${ }^{5}$ School of Nursing, The University of Texas at Austin, Austin, Texas, USA

Correspondence to Professor Peter C. Taylor; peter.taylor@kennedy.ox.ac.uk

\section{ABSTRACT}

This expert opinion article explores the strategy of adopting a holistic approach to the management of rheumatoid arthritis (RA) by incorporating the wellness practices of exercise, optimised sleep, optimised nutrition, mindfulness, social connectedness and positive emotions into the management plan. The aim is to attain optimal health for each patient beyond that achievable by limiting disease management to pharmacological treatment to attain the lowest achievable composite scores of disease activity, as recommended with the current treat-to-target approach, and addressing the recent recognition of pain control as a key patient-reported outcome. Incorporating wellness practices into a busy clinical setting requires creativity and customisation based on the individual practice setting and the individual needs of each patient. Such practices can help people living with RA to achieve optimum wellness through the introduction of measures-according to individual need - designed to improve the aspects of life most impacted for that person, thereby complementing treat-to-target and pain control strategies with pharmacological agents. Clinicians must consider wellness practices in addition to treat-to-target pharmacological agents for the holistic management of people with RA.

\section{INTRODUCTION}

Wellness can be defined as 'an active process through which people become aware of, and make choices toward, a more successful existence'. ${ }^{1}$ It is a multidimensional, holistic concept encompassing lifestyle, environment and mental and spiritual wellbeing. Wellness differs from health promotion (eg, stopping smoking) and comorbidity control (eg, lipid control to prevent heart disease) as it encompasses attitudes and active decisions that contribute to positive health outcomes. Wellness can be improved through a combination of exercise, optimum nutrition, social support, constructive coping strategies (eg, optimised sleep practices and mindfulness) and personal responsibility. ${ }^{1}$ Previous

\section{Key messages}

Wellness practices (exercise, optimised sleep, optimised nutrition, mindfulness, social connectedness and positive emotions) can help people with rheumatoid arthritis (RA) to improve their health status by reducing inflammation and symptoms (eg, stiffness, pain, fatigue) and improving functional ability and wellbeing.

- Such practices complement and enhance outcomes achievable with treat-to-target pharmacological management alone and encourage a more complete and patient-centred approach to treating RA in individuals with ongoing symptoms.

- Incorporating wellness practices into a busy clinical setting requires creativity and customisation based on the individual practice setting and the individual needs of each patient.

- Clinicians should consider wellness practices in addition to treat-to-target pharmacological agents for the holistic management of people with RA.

research highlighted the value of these wellness interventions in chronic diseases, particularly rheumatoid arthritis (RA). ${ }^{2}$

This expert opinion article explores the science and strategy of a holistic approach to treating RA by incorporating wellness practices into the management plan to help patients achieve optimal health in addition to that achievable with current treatto-target $^{3} 4$ and patient-reported outcome (PRO) improvement strategies ${ }^{5}$ supported by the use of novel antirheumatic drugs. ${ }^{6}$

\section{METHODOLOGY}

This article used references identified through non-systematic searches of the internet, including Medline and Embase, using the search terms 'rheumatoid arthritis', 'exercise', 'lifestyle', 'diet', 'sleep', 'wellness', 
Table 1 Exercise and dietary recommendations for patients with rheumatoid arthritis ${ }^{1011}$

\begin{tabular}{|c|c|c|}
\hline Exercise & Beneficial effects & $\begin{array}{l}\text { Schedule for optimum } \\
\text { results }\end{array}$ \\
\hline \multicolumn{3}{|l|}{ Exercise recommendations } \\
\hline Walking & Helps with aerobic conditioning and mood & $30-60 \mathrm{~min}, 3-5$ times/week \\
\hline Stretching & Helps with flexibility and range of motion & 10-15 min, 2 times/week \\
\hline Flowing movements & Helps with flexibility, range of motion, balance and stress & 10-15 min, 2 times/week \\
\hline Working out in water & Helps with flexibility, range of motion, aerobic conditioning and strength & $30-60 \mathrm{~min}, 3-5$ times/week \\
\hline Cycling & $\begin{array}{l}\text { Improves range of motion, aerobic conditioning, endurance and leg } \\
\text { strength }\end{array}$ & 30-60 min, 3-5 times/week \\
\hline Strength training & Helps with strength and aerobic condition & $\begin{array}{l}8-12 \text { repetitions for } 2-3 \text { sets, } \\
2-3 \text { times/week }\end{array}$ \\
\hline Hand exercises & \multicolumn{2}{|l|}{ Improves range of motion and flexibility } \\
\hline \multicolumn{3}{|c|}{ Dietary recommendations-Mediterranean diet } \\
\hline High intake & \multicolumn{2}{|c|}{$\begin{array}{l}\text { Fruit; vegetables; legumes; nuts; unrefined whole grains (whole wheat, rice, oats, corn, barley, rye); } \\
\text { unsaturated fats (olive oil, canola/rapeseed oil) }\end{array}$} \\
\hline Moderate intake & \multicolumn{2}{|l|}{ Lean meats; fish; wine } \\
\hline Low-to-moderate intake & \multicolumn{2}{|l|}{ Dairy products } \\
\hline Low intake & \multicolumn{2}{|l|}{ Red meat; processed foods; saturated fat } \\
\hline
\end{tabular}

'social support', 'mindfulness', 'positive emotions', 'selfcare', and 'patient-reported outcomes'.

\section{Exercise}

Up to $80 \%$ of patients with RA have limited exercise capacity due to joint inflammation and damage, ${ }^{7}$ leading to physical pain and functional limitation. ${ }^{8}$ Exercise prevents muscular atrophy and improves physical function by maintaining/improving muscular strength and range of motion, and reducing pain. ${ }^{9}$ Ideally, the patient, rheumatologist and physical therapist should collaborate to ensure exercise undertaken is appropriate for each disease phase to prevent further joint damage. The best exercises are walking, stretching, flowing movements, working-out in water, cycling and strength training ${ }^{1011}$ (table 1).

Perceived barriers to exercise from the perspective of patients with RA include pain, fatigue, fear of damaging joints, comorbidities, insufficient advice from healthcare providers (HCPs) and lack of time or support. ${ }^{12}$ However, regular exercise can reduce disease activity, pain and fatigue and improve physical function, sleep quality and quality of life (QoL) in patients with RA. ${ }^{11}{ }^{13-17}$ Additionally, it can improve cardiorespiratory/cardiovascular health, muscle mass and strength and reduce adiposity. $^{101315}$

Possible mechanisms for the beneficial effects of exercise in RA include stimulation of interleukin- 6 release from skeletal muscle; increased angiogenesis, leading to reduced hypoxia and associated inflammation; reduced endothelial cell production of adhesion molecules, stimulating regeneration of these cells and reduced vascular wall inflammation; reduced expression of toll-like receptors and proinflammatory cytokine production in monocytes and increased regulatory T-cell production. ${ }^{18}$

\section{Sleep}

Disturbed sleep is a major concern for people with RA. ${ }^{19}$ Many studies report relationships between pain, depression, sleep and functional disability in $\mathrm{RA}^{21}$ including interdependence in causality. ${ }^{22}$ Sleep and pain should be routinely evaluated during clinical assessments using a multidimensional PRO tool, such as the Rheumatoid Arthritis Impact of Disease Score, ${ }^{23}$ and nonpharmacological management approaches, such as physiotherapy, meditation, massage, sleep restriction therapy, sleep scheduling and imagery exercises, advised. ${ }^{24}$ Practical approaches for enhancing sleep and wellbeing are summarised in box 1 .

Poor sleep is one of the risk factors for $\mathrm{RA}^{25}$ and can lead to increased pain, fatigue, depression and anxiety. ${ }^{26}$ Lack of pain control also impacts sleep, resulting in a vicious cycle. ${ }^{27}$ Immune activation, as occurs in active RA, can disrupt both deep and dreaming sleep, leading to sleep fragmentation, feeling unrefreshed and daytime fatigue. ${ }^{28}$ Medications, such as beta-blockers, corticosteroids, analgesics and antidepressants, may further compound the problem. ${ }^{29}$ Improved sleep through effective RA management can improve disease activity measures. ${ }^{30}$

Sleep deprivation reduces ATP production and alters the lymphatic system, leading to reduced clearance of cellular waste products. Hyperphosphorylated tau and amyloid B plaques accumulate, increasing cell death and, ultimately, causing cognitive dysfunction. ${ }^{31}$ Persistent sleep disturbance activates $\beta$-adrenergic signalling, increasing inflammatory gene expression, proinflammatory cytokine production and markers of systemic inflammation. It also increases monocyte production of signal transducer and activator of transcription proteins, which 
Box 1 Techniques to promote effective sleep and improve social connectedness ${ }^{77-79}$

Promoting effective sleep

- Exercise regularly.

- Manage stress through stress-management strategies.

- Avoid daytime naps.

- Have a regular sleeping schedule; try to get 7-8 hours of sleep.

- Do not go to bed unless you are feeling sleepy.

- Avoid caffeine, alcohol, and nicotine close to bedtime.

- Do not go to bed hungry, but also do not have a heavy meal close to bedtime.

- Reduce fluid intake before bedtime.

- Avoid the use of electronic devices at least 30 min before bedtime.

- Limit exposure to bright light close to bedtime.

- Develop a relaxing bedtime routine (eg, have a warm bath, read, listen to relaxing music).

- Keep the bedroom quiet, cool and dark.

Improving social connectedness

- Join a volunteer group.

- Get involved with community activities or a cause the person is passionate about.

- Take up a hobby and join an appropriate group.

- Take up a team sport.

Keep in contact with family and friends.

mediate inflammatory cytokine signalling, and impacts the sympathetic nervous system and hypothalamic-pituitary-adrenal axis, which are also involved in inflammatory signalling. ${ }^{32}$

\section{Nutrition}

Of all the wellness behaviours with a potential impact on RA, patients are most likely to ask about diet. Currently, a Mediterranean diet is the most studied dietary recommendation, although other diets have potential antiinflammatory benefits. ${ }^{33}$ Recommended components of the Mediterranean diet are listed in table $1 .^{11}$

Studies suggest that a Mediterranean (vs nonMediterranean) diet is associated with a reduced risk of developing RA, particularly in seropositive individuals, ${ }^{3435}$ and improves inflammation, joint swelling and physical function. ${ }^{36}$ The Mediterranean diet derives its benefit from polyunsaturated fatty acids (PUFA), polyphenols and fibre. PUFA, found in oily fish and fish oils, have been shown to reduce inflammatory cytokine levels, while also increasing anti-inflammatory lipid production. ${ }^{38}$ Polyphenols-a family of phytochemicals in fruits, vegetables and olive oil-reduce oxidative stress and inflammation, while dietary fibre-in whole grains, fruit and vegetables-demonstrates anti-inflammatory properties. ${ }^{39}$ A Mediterranean diet may reduce the risk of atherosclerotic cardiovascular and cerebrovascular disease, which are increased in patients with active RA. ${ }^{40}$

HCPs should set patient expectations so dietary changes are viewed as complementary rather than an alternative to pharmacological therapy, as the benefits are likely to be modest. ${ }^{38}$ Of note, dietary effects in patients with
RA may vary with sex, serologic status, gut microbiome and hormonal status (in women) ${ }^{33-35}$ Weight loss discussions, particularly with patients who are obese, can help patients to lose weight ${ }^{41}$ and form an important first step in changing patients' weight management behaviour. ${ }^{42}$ Advice on appropriate weight-management services should be provided, while recognising factors that demotivate/motivate patients. Barriers to weight loss include pain and fatigue, limited mobility, stress, work demands and other priorities, poor psychological health, comorbidities and boredom. Appropriate advice includes increased intake of fruit, vegetables and water, switching to low calorie food/drinks, reduced intake of unhealthy foods and drink, reduced portion sizes, changes in eating habits and increased physical activity. ${ }^{43}$

\section{Mindfulness}

Mindfulness can be defined as 'the awareness that arises from paying attention, on purpose, in the present moment and non-judgmentally to the unfolding of experience moment by moment' ${ }^{44}$ Mindfulness meditation is the wellness practice most likely to be met with uncertainty, probably being a new concept for many HCPs and patients.

To demystify mindfulness, it is helpful to recommend mindfulness apps and provide a one-page handout on its benefits (reduced stress, pain, anxiety and depression and improved health and wellbeing) ${ }^{45}$ along with a list of online free guided meditations and 'how-to' suggestions $^{46}$ (table 2). Educating patients about how little time is needed to meditate is also helpful; $10 \mathrm{~min}$ of mindfulness meditation per day is beneficial, particularly in patients with anxious and repetitive thoughts, ${ }^{47}$ while 20 $\mathrm{min} /$ day for 3 days can reduce pain and anxiety. ${ }^{48}$ Tips for fitting meditation into everyday life include introducing the practice into all aspects of daily life (eg, when walking, sitting at one's desk), having a set routine, practicing for short sessions (a few minutes), using reminders (eg, a sound from a watch or computer) and using a meditation anchor (eg, observing the breath).$^{49}$

Mindfulness training can reduce disease activity, physical disability $^{170}$ and inflammation ${ }^{51}$ and improve morning stiffness, pain, fatigue, patient QoL, illness perception and psychological aspects of RA (eg, depression, anxiety, stress). ${ }^{17}$ 50-53 Stress exacerbates RA symptoms, including pain, and can cause immune dysregulation, increased proinflammatory cytokine production, cardiovascular reactivity and altered coagulation. ${ }^{54}$ Mindfulness-based stress reduction significantly increases grey matter concentration in the left hippocampus of the brain-an area involved in learning and memory processes, emotion regulation, self-referential processing and perspective taking ${ }^{55}$ —and activates brain regions that modulate pain. ${ }^{56}$

\section{Social connectedness}

One in three patients with RA believe others do not understand the impact of their disease and more than 


\begin{tabular}{ll} 
Table 2 Suggestions for practicing mindfulness ${ }^{46}$ \\
\hline Stop and breathe & $\begin{array}{l}\text { Take frequent breaks and breathe deeply several times during the day; this fosters calmness } \\
\text { and focus }\end{array}$ \\
Take time to sit still & Sit quietly in purposeful thought and reflection each day \\
Avoid filling time with activities
\end{tabular}

half feel frustrated when unable to undertake daily activities. ${ }^{57}$ Additionally, many patients believe rheumatologists do not support subjective interventions or consider patients' personal situations as part of the disease control process. However, by suggesting sources of support (eg, community groups), HCPs can help to improve an individual's social connectedness. ${ }^{58}$

Social connections with other people in the same situation and feelings of inclusion are important for physical and mental health. ${ }^{59}$ Support from family and friends is also important to help patients with RA to better understand their illness, attend appointments, adhere to treatments and eat an appropriate diet. ${ }^{60}$ Further suggestions for improving social connections are shown in box 1 .

Rewarding social relationships are known to predict better mental and physical health and greater longevity, ${ }^{61}{ }^{62}$ while loneliness and social isolation are associated with increased inflammation and poor health and wellbeing. ${ }^{63}$ Conversely, pain and physical impairment can impact patients' social and work lives. ${ }^{65}$

Social isolation promotes immune dysfunction, including proinflammatory cytokine production, and increases inflammatory markers. Such isolation may cause stress or depression that stimulates proinflammatory cytokine production and exacerbates inflammatory symptoms. ${ }^{5464}$ Additionally, social isolation may exacerbate the adverse effects of disturbed sleep on inflammation. ${ }^{32}$

\section{Positive emotions}

Positive emotions (joy, contentment, happiness, love, optimism, serenity and amusement) contribute to mental and physical wellbeing. ${ }^{6166}$ However, HCPs are often trained to focus on negative emotions and reducing symptoms. Integrating positive emotions into clinical work allows HCPs to go beyond this more traditional treatment approach. Encouraging patients to undertake an activity they enjoy is similar to prescribing exercise, social connectedness or other wellness practices; takes little time and is cost effective. Similar practices can be individualised and integrated into treatment planning and may even improve RA medication adherence. ${ }^{68}$

The link between positive emotions and physical health and longevity is well known. Positive emotions also promote positive social relationships that are reciprocally associated with physical health, ${ }^{61}$ reduce the intensity of persistent pain and buffer the effects of such pain on functioning and wellbeing in patients with RA. ${ }^{69}$

Studies have shown that positive emotions are associated with larger grey matter volume in a brain area from the left thalamus to the parahippocampal gyrus ${ }^{70}$ and activate brain areas involved in the sensing of pleasure (ventral striatum and orbital frontal cortex). ${ }^{71}$ Positive emotions are also associated with lower circulating proinflammatory cytokine levels. ${ }^{66} 6772$

\section{DISCUSSION AND 'CALL FOR ACTION'}

Treat to target has been the main approach to managing RA, based on compelling evidence for reduced joint destruction and preservation of functional status. However, many areas of contemporary unmet need are subjective aspects of key importance to the individual, such as pain reduction, improved functioning and QoL. While pharmacological interventions are needed, it is important to provide a holistic approach to treating patients to reduce pressure on healthcare systems and increase productivity. Studies have highlighted the importance of the emotional and social impact of RA and how most patients still do not feel well despite pharmacological treatment, mainly due to uncontrolled pain that impacts daily activities and wellbeing. ${ }^{57}$

As outlined in this article, wellness interventions can improve health and reduce the impact of RA on a person from both a physical and an emotional perspective. These lifestyle changes can be considered part of the overarching practice of self-management, which encompasses a variety of activities aimed at improving a person's ability to manage symptoms and treatment, and the physical and psychological consequences of a 
chronic disease. ${ }^{73}$ The importance of self-management strategies to optimise wellbeing for people living with RA has recently been recognised with the publication of EULAR recommendations ${ }^{74}$ and Portuguese multidisciplinary recommendations for non-pharmacological interventions. ${ }^{75}$ The latter include exercise, psychological interventions, social participation, sleep hygiene and selfmanagement. ${ }^{75}$ Recommended self-management strategies include problem solving, goal setting and cognitive behavioural therapy (CBT) ${ }^{74}$ CBT is a type of psychotherapy used to challenge negative thought patterns to change patient behaviours that maintain symptoms and disability; it has been shown to provide small-to-moderate improvements in impairment/disability, fatigue and selfefficacy in patients with RA. ${ }^{1776}$

This is the first article to comprehensively discuss a rationale and existing evidence for the holistic management of RA and to provide practical suggestions for incorporating wellness practices into a busy clinical setting-a process requiring creativity and customisation based on individual needs and practice settings in line with EULAR treat-to-target and self-management goals. ${ }^{47}$ Wellness is not necessarily an additional outcome to address above and beyond treat to target, as all treat-to-target metrics include the Patient Global Assessment, which is a PRO. By enhancing wellness and thereby improving patient global scores, rheumatologists may be able to improve other disease metrics (eg, the Disease Activity Score for 28-joint count and the Clinical Disease Activity Index). Whether specific RA drugs also contribute to enhanced wellness by improving key PROs connected to wellbeing (eg, pain) is not yet determined.

We call for clinicians to consider wellness practices in addition to pharmacological agents and PRO measurement for the holistic management of people with RA.

Acknowledgements The authors would like to acknowledge Dr Sue Chambers Dr loannis Nikas and Karen Goa (Rx Communications, Mold, UK) for medical writing assistance with the preparation of this article, funded by Eli Lilly and Company. PT would like to thank the National Institute of Health Research (NIHR) for their funding of the NIHR Biomedical Research Centre in Musculoskeletal Disease at Oxford University Hospitals NHS Trust and University of Oxford.

Contributors Conception of the work: PT, MVdL, IdIT, WF and AQ. Design of the work: PT, IdIT, WF and AQ. Acquisition of data for the work and analysis of data for the work: PT, SJ, AL, IdIT, WF and AQ. Interpretation of data for the work, drafting of the article, critical revision of the article for important intellectual content, approval and sufficient participation in the work to agree to be accountable for all aspects of the work in ensuring that questions related to the accuracy or integrity of any part of the work are appropriately investigated and resolved: all authors.

Funding This article was funded by Eli Lilly and Company.

Competing interests PT: Research grants from Celgene and Galapagos and consultation fees from AbbVie, Biogen, Galapagos, Gilead, GlaxoSmithKline, Janssen, Lilly, Pfizer, BMS, Roche, Sanofi, Nordic Pharma, Fresenius and UCB. SJ has served as a consultant, member of advisory boards and/or speaker bureaus for Eli Lilly, Otsuka, Pamlab and Sunovion. MVdL reports educational grants and speaker's-advisory fees from Eli Lilly and Company not related to this work. AL has been member of speaker bureaus for Lilly, Novartis, Amgen, Exage, Myria and Pfizer and a consultant for Amgen. WF, AQ and IdIT are employees of Eli Lilly and Company.

Patient consent for publication Not applicable.

Ethics approval This study does not involve human participants.

Provenance and peer review Not commissioned; externally peer reviewed.
Open access This is an open access article distributed in accordance with the Creative Commons Attribution Non Commercial (CC BY-NC 4.0) license, which permits others to distribute, remix, adapt, build upon this work non-commercially, and license their derivative works on different terms, provided the original work is properly cited, appropriate credit is given, any changes made indicated, and the use is non-commercial. See: http://creativecommons.org/licenses/by-nc/4.0/.

\section{ORCID iDs}

Peter C. Taylor http://orcid.org/0000-0001-7766-6167

Amanda Quebe http://orcid.org/0000-0001-6705-8045

\section{REFERENCES}

1 National Wellness Institute. The six dimensions of wellness. Available: https://nationalwellness.org/resources/six-dimensions-ofwellness/ [Accessed 12 Oct 2020].

2 Stuifbergen AK, Morris M, Jung JH, et al. Benefits of wellness interventions for persons with chronic and disabling conditions: a review of the evidence. Disabil Health J 2010;3:133-45.

3 Fraenkel L, Bathon JM, England BR, et al. American College of Rheumatology guideline for the treatment of rheumatoid arthritis. Arthritis Rheumatol 2021;2021:1108-23.

4 Smolen JS, Landewé RBM, Bijlsma JWJ, et al. EULAR recommendations for the management of rheumatoid arthritis with synthetic and biological disease-modifying antirheumatic drugs: 2019 update. Ann Rheum Dis 2020;79:685-99.

5 Fautrel B, Alten R, Kirkham B, et al. Call for action: how to improve use of patient-reported outcomes to guide clinical decision making in rheumatoid arthritis. Rheumatol Int 2018;38:935-47.

6 Fautrel B, Zhu B, Taylor PC, et al. Comparative effectiveness of improvement in pain and physical function for baricitinib versus adalimumab, tocilizumab and tofacitinib monotherapies in rheumatoid arthritis patients who are naïve to treatment with biologic or conventional synthetic disease-modifying antirheumatic drugs: a matching-adjusted indirect comparison. RMD Open 2020;6:e001131.

7 Sokka T, Häkkinen A. Poor physical fitness and performance as predictors of mortality in normal populations and patients with rheumatic and other diseases. Clin Exp Rheumatol 2008;26:S14-20.

8 Smolen JS, Aletaha D, Mclnnes IB. Rheumatoid arthritis. Lancet 2016;388:2023-38

9 Hurkmans E, van der Giesen FJ, Vliet Vlieland TP, et al. Dynamic exercise programs (aerobic capacity and/or muscle strength training) in patients with rheumatoid arthritis. Cochrane Database Syst Rev 2009;2009:CD006853.

10 Cooney JK, Law R-J, Matschke V, et al. Benefits of exercise in rheumatoid arthritis. J Aging Res 2011;2011:681640

11 Saulle R, La Torre G. The Mediterranean diet, recognized by UNESCO as a cultural heritage of humanity. Ital $J$ Public Health 2010;7:414-5.

12 Veldhuijzen van Zanten JJCS, Rouse PC, Hale ED, et al. Perceived barriers, facilitators and benefits for regular physical activity and exercise in patients with rheumatoid arthritis: a review of the literature. Sports Med 2015;45:1401-12.

13 de Jong Z, Munneke M, Kroon HM, et al. Long-term follow-up of a high-intensity exercise program in patients with rheumatoid arthritis. Clin Rheumatol 2009;28:663-71.

14 Durcan L, Wilson F, Cunnane G. The effect of exercise on sleep and fatigue in rheumatoid arthritis: a randomized controlled study. J Rheumatol 2014;41:1966-73.

15 Manning VL, Hurley MV, Scott DL, et al. Education, selfmanagement, and upper extremity exercise training in people with rheumatoid arthritis: a randomized controlled trial. Arthritis Care Res 2014;66:217-27.

16 Ambrosino P, lannuzzi GL, Formisano R, et al. Exergaming as an additional tool in rehabilitation of young patients with rheumatoid arthritis: a pilot randomized controlled trial. Games Health J 2020;9:368-75.

17 Marques A, Santos E, Nikiphorou E, et al. Effectiveness of selfmanagement interventions in inflammatory arthritis: a systematic review informing the 2021 EULAR recommendations for the implementation of self-management strategies in patients with inflammatory arthritis. RMD Open 2021;7:e001647.

18 You T, Arsenis NC, Disanzo BL, et al. Effects of exercise training on chronic inflammation in obesity: current evidence and potential mechanisms. Sports Med 2013;43:243-56.

19 Drewes AM, Nielsen KD, Hansen B, et al. A longitudinal study of clinical symptoms and sleep parameters in rheumatoid arthritis. Rheumatology 2000;39:1287-9. 
20 Kirwan J, Heiberg T, Hewlett S, et al. Outcomes from the patient perspective workshop at OMERACT 6. J Rheumatol 2003;30:868-72.

21 Luyster FS, Chasens ER, Wasko MCM, et al. Sleep quality and functional disability in patients with rheumatoid arthritis. J Clin Sleep Med 2011;7:49-55.

22 Wolfe F, Michaud K, Li T. Sleep disturbance in patients with rheumatoid arthritis: evaluation by medical outcomes study and visual analog sleep scales. J Rheumatol 2006;33:1942-51.

23 Gossec L, Dougados M, Rincheval N, et al. Elaboration of the preliminary Rheumatoid Arthritis Impact of Disease (RAID) score: a EULAR initiative. Ann Rheum Dis 2009;68:1680-5.

24 Tang NKY, Lereya ST, Boulton $\mathrm{H}$, et al. Nonpharmacological treatments of insomnia for long-term painful conditions: a systematic review and meta-analysis of patient-reported outcomes in randomized controlled trials. Sleep 2015;38:1751-64.

25 Sivertsen B, Lallukka T, Salo P, et al. Insomnia as a risk factor for ill health: results from the large population-based prospective HUNT study in Norway. J Sleep Res 2014;23:124-32.

26 Irwin MR, Olmstead R, Carrillo C, et al. Sleep loss exacerbates fatigue, depression, and pain in rheumatoid arthritis. Sleep 2012;35:537-43.

27 Grabovac I, Haider S, Berner C, et al. Sleep quality in patients with rheumatoid arthritis and associations with pain, disability, disease duration, and activity. J Clin Med 2018;7:336.

28 Besedovsky L, Lange T, Haack M. The sleep-immune crosstalk in health and disease. Physiol Rev 2019;99:1325-80.

29 Van Gastel A. Drug-Induced insomnia and excessive sleepiness. Sleep Med Clin 2018;13:147-59.

30 Wells G, Li T, Tugwell P. Investigation into the impact of abatacept on sleep quality in patients with rheumatoid arthritis, and the validity of the MOS-sleep questionnaire sleep disturbance scale. Ann Rheum Dis 2010;69:1768-73.

31 Lucke-Wold BP, Smith KE, Nguyen L, et al. Sleep disruption and the sequelae associated with traumatic brain injury. Neurosci Biobehav Rev 2015;55:68-77.

32 Irwin MR, Opp MR. Sleep health: reciprocal regulation of sleep and innate immunity. Neuropsychopharmacol Rev 2017;42:129-55.

33 Coras R, Murillo-Saich JD, Guma M. Circulating pro- and antiinflammatory metabolites and its potential role in rheumatoid arthritis pathogenesis. Cells 2020;9:827.

$34 \mathrm{Hu}$ Y, Sparks JA, Malspeis S, et al. Long-term dietary quality and risk of developing rheumatoid arthritis in women. Ann Rheum Dis 2017;76:1357-64.

35 Johansson K, Askling J, Alfredsson L, et al. Mediterranean diet and risk of rheumatoid arthritis: a population-based case-control study. Arthritis Res Ther 2018;20:175.

36 Sköldstam L, Hagfors L, Johansson G. An experimental study of a Mediterranean diet intervention for patients with rheumatoid arthritis. Ann Rheum Dis 2003;62:208-14.

37 Vadell AKE, Bärebring L, Hulander E, et al. Anti-inflammatory diet in rheumatoid arthritis (ADIRA)-a randomized, controlled crossover trial indicating effects on disease activity. Am J Clin Nutr 2020;111:1203-13.

38 Miles EA, Calder PC. Influence of marine $n-3$ polyunsaturated fatty acids on immune function and a systematic review of their effects on clinical outcomes in rheumatoid arthritis. Br J Nutr 2012;107:S171-84.

39 Bustamante MF, Agustín-Perez M, Cedola F, et al. Design of an antiinflammatory diet (ITIS diet) for patients with rheumatoid arthritis. Contemp Clin Trials Commun 2020;17:100524.

40 Crowson CS, Liao KP, Davis JM, et al. Rheumatoid arthritis and cardiovascular disease. Am Heart J 2013;166:622-8.

41 Pool AC, Kraschnewski JL, Cover LA, et al. The impact of physician weight discussion on weight loss in US adults. Obes Res Clin Pract 2014;8:e131-9.

42 Halbert $\mathrm{CH}$, Jefferson M, Melvin CL, et al. Provider advice about weight loss in a primary care sample of obese and overweight patients. J Prim Care Community Health 2017;8:239-46.

43 Evans EH, Sainsbury K, Kwasnicka D, et al. Support needs of patients with obesity in primary care: a practice-list survey. BMC Fam Pract 2018;19:6.

44 Kabat-Zinn J. Mindfulness-based interventions in context: past, present, and future. Clin Psychol Sci Prac 2003;10:144-56.

45 Tang Y-Y, Leve LD. A translational neuroscience perspective on mindfulness meditation as a prevention strategy. Trans/ Behav Med 2016;6:63-72.

46 Cleveland Clinic. Practice mindfulness to improve your well-being: 11 tips, 2018. Available: https://health.clevelandclinic.org/practicemindfulness-to-improve-your-well-being-11-tips/ [Accessed 8 Dec 2020].
47 Xu M, Purdon C, Seli P, et al. Mindfulness and mind wandering: the protective effects of brief meditation in anxious individuals. Conscious Cogn 2017;51:157-65.

48 Zeidan F, Gordon NS, Merchant J, et al. The effects of brief mindfulness meditation training on experimentally induced pain. $J$ Pain 2010;11:199-209.

49 Shonin E, Van Gordon W, Griffiths MD. Practical tips for using mindfulness in general practice. Br J Gen Pract 2014;64:368-9.

50 El Miedany Y, El Gaafary M, El Arousy N, et al. Arthritis education: the integration of patient-reported outcome measures and patient self-management. Clin Exp Rheumatol 2012;30:899-904.

51 Fogarty FA, Booth RJ, Gamble GD, et al. The effect of mindfulnessbased stress reduction on disease activity in people with rheumatoid arthritis: a randomised controlled trial. Ann Rheum Dis 2015;74:472-4

52 Zangi HA, Mowinckel P, Finset A, et al. A mindfulness-based group intervention to reduce psychological distress and fatigue in patients with inflammatory rheumatic joint diseases: a randomised controlled trial. Ann Rheum Dis 2012;71:911-7.

53 Dalili Z, Bayazi MH. The effectiveness of mindfulness-based cognitive therapy on the illness perception and psychological symptoms in patients with rheumatoid arthritis. Complement Ther Clin Pract 2019;34:139-44.

54 Liu Y-Z, Wang Y-X, Jiang C-L. Inflammation: the common pathway of stress-related diseases. Front Hum Neurosci 2017;11:316.

55 Hölzel BK, Carmody J, Vangel M, et al. Mindfulness practice leads to increases in regional brain gray matter density. Psychiatry Res 2011;191:36-43.

56 Zeidan F, Emerson NM, Farris SR, et al. Mindfulness meditationbased pain relief employs different neural mechanisms than placebo and sham mindfulness meditation-induced analgesia. $J$ Neurosci 2015;35:15307-25

57 Alten R, van de Laar M, De Leonardis F, et al. Physical and emotiona burden of rheumatoid arthritis: data from RA matters, a web-based survey of patients and healthcare professionals. Rheumatol Ther 2019;6:587-97.

58 Mossabir R, Morris R, Kennedy A, et al. A scoping review to understand the effectiveness of linking schemes from healthcare providers to community resources to improve the health and well-being of people with long-term conditions. Health Soc Care Community 2015;23:467-84.

59 My Health My Community. Social connection and health, 2019. Available: https://myhealthmycommunity.org/wp-content/uploads/ 2019/05/MHMC SocialConnections web.pdf [Accessed 9 Dec 2020]

60 Ginsberg S. Caregivers are vital to arthritis management. Rheumatology Network, 2017. Available: https://www. rheumatologynetwork.com/view/caregivers-are-vital-arthritismanagement [Accessed 24 Jun 2021].

61 Kok BE, Coffey KA, Cohn MA, et al. How positive emotions build physical health: perceived positive social connections account for the upward spiral between positive emotions and vagal tone. Psychol Sci 2013;24:1123-32.

62 Pillemer S, Holtzer R, Blumen HM. Functional connectivity associated with social networks in older adults: a resting-state fMRI study. Soc Neurosci 2017;12:242-52.

63 Hawkley LC, Cacioppo JT. Loneliness matters: a theoretical and empirical review of consequences and mechanisms. Ann Behav Med 2010;40:218-27.

64 Yang YC, Li T, Frenk SM. Social network ties and inflammation in U.S. adults with cancer. Biodemography Soc Biol 2014;60:21-37.

65 Schneider M, Manabile E, Tikly M. Social aspects of living with rheumatoid arthritis: a qualitative descriptive study in Soweto, South Africa - a low resource context. Health Qual Life Outcomes 2008;6:54.

66 Stellar JE, John-Henderson N, Anderson CL, et al. Positive affect and markers of inflammation: discrete positive emotions predict lower levels of inflammatory cytokines. Emotion 2015;15:129-33.

67 Moreno PI, Moskowitz AL, Ganz PA, et al. Positive affect and inflammatory activity in breast cancer survivors: examining the role of affective arousal. Psychosom Med 2016;78:532-41.

68 Rodrigues JR, Faria DS, Neves JS, et al. Positive affect as a predictor of adherence in patients with rheumatoid arthritis. Acta Reumatol Port 2019;44:132-7.

69 Hanssen MM, Peters ML, Boselie JJ, et al. Can positive affect attenuate (persistent) pain? State of the art and clinical implications. Curr Rheumatol Rep 2017;19:80.

70 Yang J, Wei D, Wang K, et al. Gray matter correlates of dispositional optimism: a voxel-based morphometry study. Neurosci Lett 2013:553:201-5. 
71 Burgdorf J, Panksepp J. The neurobiology of positive emotions. Neurosci Biobehav Rev 2006;30:173-87.

72 Matsunaga M, Isowa T, Yamakawa K, et al. Association between perceived happiness levels and peripheral circulating pro-

inflammatory cytokine levels in middle-aged adults in Japan. Neuro Endocrinol Lett 2011;32:458-63.

73 Zuidema RM, Repping-Wuts H, Evers AWM, et al. What do we know about rheumatoid arthritis patients' support needs for selfmanagement? A scoping review. Int J Nurs Stud 2015;52:1617-24.

74 Nikiphorou E, Santos EJF, Marques A, et al. EULAR recommendations for the implementation of self-management strategies in patients with inflammatory arthritis. Ann Rheum Dis 2021;2021:1278-85.

75 Santos EJF, Duarte C, Ferreira RJO, et al. Portuguese multidisciplinary recommendations for non-pharmacological and non-surgical interventions in patients with rheumatoid arthritis. Acta Reumatol Port 2021;46:40-54.

76 Hewlett S, Ambler N, Almeida C, et al. Self-management of fatigue in rheumatoid arthritis: a randomised controlled trial of group cognitivebehavioural therapy. Ann Rheum Dis 2011;70:1060-7.

77 Martino J, Pegg J, Frates EP. The connection prescription: using the power of social interactions and the deep desire for connectedness to empower health and wellness. Am J Lifestyle Med 2015;11:466-75.

78 Irish LA, Kline CE, Gunn HE, et al. The role of sleep hygiene in promoting public health: a review of empirical evidence. Sleep Med Rev 2015;22:23-36.

79 Sleep Education. Healthy sleep habits, 2020. Available: https:// sleepeducation.org/healthy-sleep/healthy-sleep-habits/ [Accessed 24 Jun 2021]. 